\title{
Comunicação, dispositivo e espaço corporativo: a estratégia da promessa na dinâmica das organizações no capitalismo
}

Communications, device and corporate space: the strategy of promise in the dynamics of organizations in capitalism

Comunicación, dispositivo y espacio corporativo: la estrategia de la promesa en la dinámica de las organizaciones en el capitalismo

\section{(9) Daniela Norcia Gonçalves}

- Centro Interdisciplinar de Pesquisas em Comunicação e Cibercultura da Pontifícia Universidade Católica de São Paulo (PUC-SP).

- E-mail: daniela.norcia@gmail.com

\section{(9) Eugênio Trivinho}

- Programa de Estudos Pós-Graduados em Comunicação e Semiótica da PUC-SP.

- E-mail: eugeniotrivinho@uol.com.br 


\section{Resumo}

0 artigo reflete sobre o dispositivo de comunicação e seu desdobramento corporativo como promessa da comunicação. A temática, pouco presente em estudos brasileiros sobre comunicação organizacional e afins, comparece fortemente na produção teórica francesa das duas últimas décadas. Inspirado na biopolítica de Michel Foucault e em abordagens francesas sobre o dispositivo de comunicação, o texto apreende a relação entre espaço corporativo e macrodispositivo do social, abrindo caminho para caracterizar a promessa da comunicação como estratégia inseparável da reprodução do capitalismo.

\section{PALAVRAS-CHAVE: ORGANIZAÇÕES CORPORATIVAS • COMUNICAÇÃO ORGANIZACIONAL • DISPOSITIVO DE COMUNICAÇÃO • PROMESSA DA COMUNICAÇÃO • MACRODISPOSITIVO DO SOCIAL.}

\section{Abstract}

The article reflects on the communications device and its corporate manifestation as a communications promise. Little known in Brazilian studies on organizational communication, this theme strongly figures in the French theoretical production in the past two decades. Based on Michel Foucault's biopolitics and French approaches on the communications device, the paper apprehends the relationship between the corporate space and the macro-dispositive of the social to characterize the communication promise as an inherent strategy of the reproduction of capitalism.

KEYWORDS: CORPORATE ORGANIZATIONS• ORGANIZATIONAL COMMUNICATION • COMMUNICATIONS DEVICE • PROMISE OF COMMUNICATIONS• SOCIAL MACRODEVICE.

\section{Resumen}

El artículo aborda el dispositivo de comunicación y su despliegue corporativo como promesa de comunicación. Poco conocido en los estudios brasileños sobre comunicación organizacional, el tema se examinó en la producción teórica francesa de las dos últimas décadas. Inspirado en la biopolítica de Michel Foucault y los enfoques franceses sobre el dispositivo comunicacional, el texto aprehende la relación entre espacio corporativo y macrodispositivo de lo social para posteriormente caracterizar la promesa de la comunicación como una estrategia de reproducción capitalista. 


\section{NOTA INTRODUTÓRIA}

A Iguém que, diante de um telejornal francês, ouça com atenção a fala de especialistas e políticos entrevistados não tardará a notar a circulação de um termo intrigante: dispositivo. No âmbito das universidades daquele país, o termo comparece com frequência. Esculpido na obra de Michel Foucault (1982, 1987, 2005, 2008a, 2008b) e explorado por Deleuze (1991, 1996, 1999), Agamben (2005, 2006, 2009) e Žižek (2003), o vocábulo integra o repertório político e comunicacional da cultura francesa na forma da expressão conceitual dispositivo de comunicação. Sua voga neste século acabou por suscitar, em 2010, a publicação de uma obra coletiva intitulada Les dispositifs de communication et de l'information (Os dispositivos de comunicação e de informação, em tradução literal).

No Brasil e na América Latina, o conceito não encontrou uso político, social e cultural tão difundido. Fora do contexto universitário, por exemplo, o dispositivo comparece como sinônimo de cláusula legal e de tecnologia ou recurso de comunicação, como 0 telefone celular e o GPS, entre outros devices. No espaço acadêmico, especialmente no que tange à produção bibliográfica, a utilização do conceito envolve abordagens nas áreas de Comunicação, da Ciência da Informação, da Ciência da Computação, do Direito e das Ciências Sociais. Em particular na primeira delas, não é tão comum o uso do termo no campo de estudos da comunicação organizacional. A argumentação a seguir, assentada em caráter de sinalização reflexiva, é uma contribuição preliminar para a superação dessa lacuna'. Inspirada nas Ciências Humanas, ela se destina ao público especializado das áreas de Comunicação e Administração, especialmente na segmentação da Propaganda, da Publicidade, do Marketing, das Relações Públicas e afins. Por evidente, ela recobre linhas de interesse específico do público especializado das áreas de Sociologia, Ciência Política e Direito, voltado para as formas de administração, gerenciamento e controle das organizações corporativas e estatais, bem como dos aglomerados populacionais de modo geral. Tal lugar de fala do estudo e seus destinatários contratam reflexão com características e finalidades definidas: ela deve ser recenseadora (sobre o dispositivo), analítica (no que tange à demonstração e elucidação descritivas) e crítica (pressupondo exame criterioso e dissecação da lógica política, social e econômica em jogo).

\section{O DISPOSITIVO NO CAMPO DE ESTUDOS DA COMUNICAÇÃO E DA INFORMAÇÃO}

De acordo com Appel, Boulanger e Massou (2010, p.11), a maioria dos usos da noção de dispositivo, quando situada nas áreas de Comunicação e Ciência da Informação, dentro e fora da França, apoia-se, direta ou indiretamente, numa entrevista de Michel Foucault, concedida em 1977 para a revista Ornicar?. Nessa ocasião, o filósofo francês afirmou que o dispositivo resulta de um conjunto heterogêneo de elementos discursivos e não discursivos. Segundo os autores, no entanto, raramente os interessados (ao menos franceses) na matéria evocam a formulação biopolítica original desse conceito, deixando escapar seu valor biopolítico e sociocultural fundamental, bem como um de seus aspectos cruciais, expresso em sua "natureza essencialmente estratégica [...], como manipulação ou intervenção racional e calculada de relações de força, jogo ou apostas de poder em relação com tipos de saber"2 (Appel; Boulanger; Massou, 2010, p.11, tradução nossa). Essa interpretação se alinha ao tratamento subsequente dado por Foucault (1982, p.244-247) à matéria.

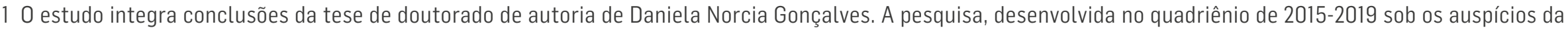

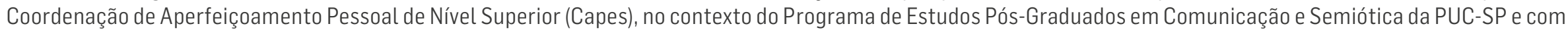

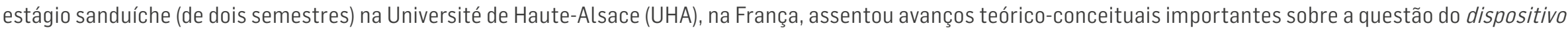

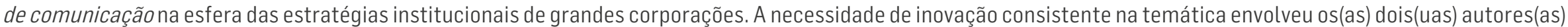
em vários momentos de reflexão conjunta ao longo da investigação e da argumentação do presente texto, referenciado no segundo capítulo da mencionada tese.

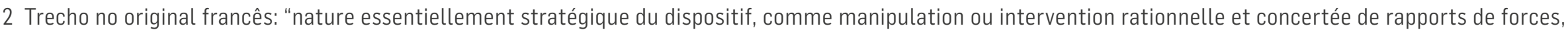
jeu ou enjeux de pouvoir en lien avec des types de savoir".
} 
Em interpretação livre, o conceito de dispositivo remete, grosso modo, a uma tessitura complexa de discursos linguísticos (manifestações verbais organizadas, corpus de legislação, jogos de opinião aleatórios etc.) e narrativas averbais e pressupostos ágrafos (imagens, hábitos, gestos, procedimentos, valores etc.), com seus interditos e permissões, modos de engendramento e circunscrições, objetos técnicos e fatores de condutibilidade, além, evidentemente, de suas instâncias de produção, promoção e reprodução, e de seus processos de eternização. 0 dispositivo se configura, social e culturalmente, como "um mundo", sem jamais se entregar como político e/ou ideológico. Tão objetivo quanto inquestionável - e assim vivenciado como verdadeiro per se na e pela percepção e senso comuns -, suas características se confundem com as necessidades diuturnas do próprio processo sociocultural de consolidação de subjetividades e de modos de subjetivação de mundo (isto é, de ser, estar, pensar, sentir e agir nele), em conformidade com a mencionada tessitura complexa de fatores interconstitutivos.

Nesse horizonte, Isabelle Gavillet (2010) chama atenção, na área de estudos da comunicação e da informação, para três dimensões da ideia foulcaultiana de dispositivo: o mencionado conjunto estritamente heterogêneo de elementos discursivos e não discursivos, a natureza da intersecção entre eles e, mais especificamente, 0 arranjamento conjunto destinado a responder a uma urgência. Para Gavillet (2010, p.19), o dispositivo encerra uma visão propriamente política (lato sensu) da administração das sociedades contemporâneas e de suas instituições. Essa concepção subordina o conceito a uma formulação mais estratégica do que técnica com foco prioritário: a da governabilidade, isto é, a ascendência macroestrutural e política de um feixe de poderes e saberes sobre corpos e gêneros, subjetividades e formas de subjetivação em determinada época social-histórica.

Gavillet (2010) afirma que, para Foucault, o poder sintetizava a questão essencial do século XX (e, poder-se-ia dizer, também para depois desse marco temporal). A autora lembra que o filósofo considerava que "esse problema foi mal compreendido no passado, o que teve consequências fatais, porque foi colocado exclusivamente em termos de Estado e da soberania e não em termos de disciplina, ou seja, de configuração de poder e de saber constitutivos do sujeito"3 (Gavillet, 2010, p.32).

Na esteira da concepção inaugurada por Foucault, três importantes publicações refletem sobre a matéria: "Qu'est-ce qu'un dispositif?" (0 que é um dispositivo?), de Gilles Deleuze (1989); "Che cosè un dispositivo?" (idem ao título anterior em português), de Giorgio Agamben (2006); e uma edição da revista Hermès, de 1999, dedicada exclusivamente ao dispositivo (Jacquinot-Delaunay; Monnoyer, 1999). A partir de 1977, a pesquisa francesa, em particular sobre questões comunicacionais, se enriqueceu bastante ao incorporar diversas apropriações desse conceito. Nesse campo de estudos, Appel e Heller (2010, p.39) notam tal incremento em periódicos científicos e revistas acadêmicas, especialmente em edições temáticas e dossiês.

De acordo com levantamento realizado por Daniela Norcia Gonçalves (2019) e Appel e Heller (2010) desenvolveram uma tipologia do dispositivo que evidencia formas distintas de tratá-lo no plano epistemológico. Essa tipologia abrange desde objetos temáticos específicos (no elenco dos quais os autores veem o dispositivo no contexto de suas próprias pesquisas, ligado a uma categorização, ou melhor, a uma lógica analítica e crítica) até o dispositivo como objeto de reflexão em si mesmo. De acordo com a autora,

um primeiro nível adotado é relacionado à descrição de um objeto ou uma questão, como dispositivos metodológicos que permitem a observação das práticas de comunicação e que se tornam úteis por dar conta das dinâmicas sociais engendradas na produção de documentos provenientes das organizações. Entre os exemplos estão os dispositivos intermediários de escrita que permitem uma reflexão sobre a escrita como uma fala, os idiomáticos de um hospital, os técnicos que introduzem uma mutação na relação dos sistemas de informações jornalísticas sobre acontecimentos, o dispositivo de reunião, a pesquisa-ação e, enfim, os dispositivos de tratamento de informações. [...] A essa aplicação do conceito eles darão o nome de logique d'agencement, o que podemos chamar, em português, de uma lógica de organização, de mapeamento, de um traçado, de integrar harmoniosamente os elementos.

3 Trecho no original: "ce problème a été mal compris dans le passé, ce qui a eu des conséquences fatales, parce qu'on l'a posé exclusivement en termes d'État et de souveraineté et non en termes de discipline, c'est-à-dire de configuration de pouvoir et de savoir constituant de sujet". 
Um segundo nível de sentido de dispositivo encontrado por Appel e Heller, intitulado de logique analytique (lógica analítica) é 0 que o coloca como um processo de coconstrução social/técnica e co-construção de sentido. Assim, a comunicação é, por um lado, vista como construção social com uma filiação com a pesquisa sociológica e, por outro, como construção de sentido com uma filiação às ciências da linguagem. (Gonçalves, 2019, p.112, grifo da autora)

No âmbito desses dois níveis, o conceito de dispositivo abarca, segundo Appel e Heller (2010, p.43, tradução nossa), "um conjunto de condições da comunicação" e, como tal, lastreia, como instrumento teórico-analítico, a possibilidade de uma "abordagem processual da comunicação que implica em um sujeito/ator e enunciados ou tecnologias, em uma relação de produção de sentido ou produção social (ou sócio-organizacional)"4.

Os autores identificam, ainda, um terceiro nível semântico-epistemológico, no qual posicionam uma logique critique do dispositivo, isto é, uma lógica interna que abrange seus efeitos ou fins políticos. 0 dispositivo comparece então, em suas aplicações possíveis, como uma ferramenta e, portanto, como construção política.

\section{Dispositivo e comunicação nas organizações corporativas}

Não por outra razão, do ponto de vista da comunicação nas organizações, Appel e Heller (2010) ponderam que a comunicação gerencial e o dispositivo comunicacional podem emparelhar as respectivas características se não se perder de vista que, sob a ótica crítica, a comunicação gerencial, para funcionar nessa direção, precisa, necessariamente, considerar que

as contradições das relações sociais de produção ou as contradições do capitalismo constituem a matriz da comunicação gerencial, na qual as questões estão bem expressadas na formulação de Michel Foucault sobre as disciplinas: maximizar a força útil dos funcionários, minimizando a força política deles. (Appel; Heller, 2010, p.46, tradução nossa) ${ }^{5}$

A diferença sinalizada se deve ao fato de que, para os autores, a natureza do dispositivo é essencialmente estratégica. Ele sempre implica certa manipulação de forças, seja para bloqueá-las ou liberá-las, seja para estabilizá-las ou redirecioná-las. 0 dispositivo está sempre inscrito em um jogo de poder; melhor, o dispositivo é, antes, o princípio organizador de uma tecnologia de poder. Dessa forma, o conceito implica

no nível da prática científica, uma postura analítica (descrição de tecnologias de poder) e crítica (notadamente de instauração das lutas de poder e/ou de dominação por um conjunto de elementos ditos e não ditos, num contexto de relações de força que estabelece o sentido ou o alvo do dispositivo). [...] 0 conceito de dispositivo convoca as noções-objeto (sujeito, saber) que, na articulação do poder, levam a questionamentos específicos, esboçam linhas de pesquisa: no domínio da comunicação organizacional, ele convida aos questionamentos sobre as relações entre poder e saber em matéria de comunicação, sobre os saberes investidos nos dispositivos de comunicação ou, ainda, sobre os processos no trabalho de construção do sujeito e sobre a figura do sujeito inscrita nos dispositivos concretos. (Appel; Heller, 2010, p.46-47, tradução nossa) ${ }^{6}$

\footnotetext{
4 No original: [o conceito se refere a] "un ensemble des conditions de la communication. Dans cette logique le dispositif est donc envisagé comme concept analytique d'une approche processuelle de la communication qui implique un sujet/acteur et des énoncés ou des technologies, dans une relation de production de sens ou de production sociale (ou socio-organisationnelle)".

5 No original: "les contradictions des rapports sociaux de production ou les contradictions du capitalisme constituent la matrice de la communication managériale, dont les enjeux sont assez bien exprimés dans cette formule de Michel Foucault à propos des disciplines: maximiser la force utile des salariés tout en minimisant leur force politique". enjeux de pouvoir et/ou de domination d'un réseau d'éléments de dit et de non-dit, dans un contexte de rapports de force que fixe donc le sens ou la visée du dispositif). [...] Le concept de dispositif convoque des notions-objets (sujet, savoir), qui, dans leur articulation au pouvoir, renvoient à des questionnements sur les rapports entre pouvoir et savoir en matière de communication, sur les savoirs investis dans les dispositifs de communication, ou encore sur les processus à l'œuvre dans la construction du sujet, et sur la figure du sujet inscrite dans les dispositifs concrets".
} 
A prioridade dada a essa colocação sobreleva, aqui, a questão do dispositivo de comunicação, fundamental para a (compreensão da) dinâmica de sobrevivência das organizações corporativas numa sociedade articulada por media de todos os matizes.

Para Appel e Heller (2010), essa expressão conceitual, abrangendo níveis articulados de apreensão do objeto precípuo em jogo a própria função estrutural da comunicação no social contemporâneo -, envolve discursos, comportamentos, interações e, naturalmente, tecnologias de informação e comunicação. Aprofundando o argumento, os autores tocam num ponto crucial ao apreenderem, na designação do conceito, "a comunicação como princípio organizador das relações de poder" (Appel; Heller, 2010, p.48). Eles reconhecem que essa asserção não significa que o dispositivo de comunicação seja o princípio articulatório exclusivo ou o mais frutífero no espaço corporativo. Todavia, admitindo a centralidade da comunicação nesse contexto, afirmam ver o dispositivo de comunicação como um fator tão dominante - e, poder-se-ia dizer, em interpretação livre, tão remodulador das relações entre discursos, comportamentos, interações e tecnologias - que até seria capaz de suplantar a lógica dissecada por Foucault do modelo disciplinar. A validade dessa consideração reside no deslocamento do foco analítico para o recorte das "práticas de comunicação", sob o fundamento de que "o alvo do poder não está limitado ao corpo", como faz crer equivocadamente uma tomada superficial da obra de Foucault; antes, o alvo do poder "se estende ao espírito ou à psique" (Appel; Heller, 2010, p.48-49)7.

Seja como for, a conclusão de Appel e Heller (2010), à luz da mencionada tipologia que propõem, não deixa de incluir, com efeito, a consideração de que os usos do conceito de dispositivo nas pesquisas sobre comunicação organizacional confluem, em regra, para uma direção relativamente comum, sem, no entanto, ser deliberadamente consensual. Variando em relação ao papel da informação e da comunicação na organização e na sociedade, na prática, tais usos visariam

a organização de elementos mais ou menos heterogêneos e aplicada à cozinha científica (construção do objeto e a construção metodológica ou epistemológica) na qual se integra uma dupla orientação que exprime ainda mais uma postura de pesquisa, uma escolha epistemológica e reendereça a pesquisa a apostas diferentes, analíticas e críticas. (Appel; Heller, 2010, p.53, tradução nossa) ${ }^{8}$

\section{OS DISPOSITIVOS DE ACESSO À INFORMAÇÃO (DAI)}

Outra vertente de abordagem das relações entre dispositivo e comunicação organizacional está umbilicalmente vinculada às tecnologias digitais e redes interativas. A partir dos anos 1970, com o enraizamento da internet, da web e dos smartphones na vida cotidiana, as companhias integraram, em sua infraestrutura e dinâmica operacional, um estrato multimediático no qual passaram a atuar mediante criação e fomentação de plataformas e websites, contas e perfis em redes sociais etc. para anúncios e campanhas publicitárias, além de appse ferramentas similares para disseminação de mensagens e desenvolvimento de interações internas e com fornecedores e clientes. Nesse universo, situam-se os dispositivos de acesso à informação(DAI).

Brigitte Simonnot (2010, p.96-99) afirma que os DAl, que têm substituído a noção de sistema de pesquisa de informações, podem ser distinguidos segundo três aspectos: a natureza das informações objeto de acesso, a política que define a coleta de informações e a organização dos dispositivos. De acordo com a autora, os DAl, de existência recente, também podem ser

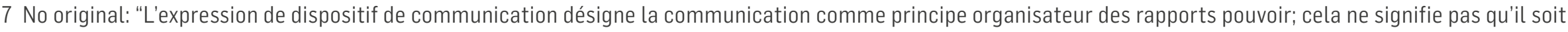

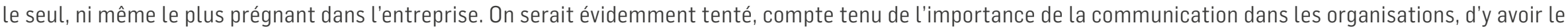

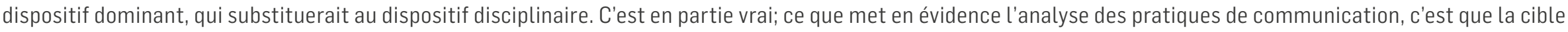
du pouvoir n'est pas limitée au corps, mais s'étend à l'esprit ou la psyché".

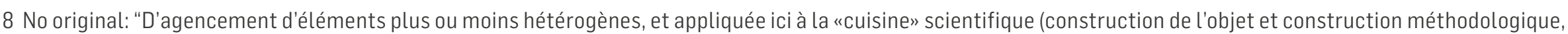

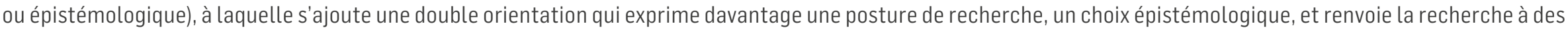
enjeux différents, analytique et critique".
} 
classificados com base em fatores de necessidade, a saber: a necessidade em si das informações, a duração dessa necessidade, se ela é individual ou coletiva, e sua especificidade no tocante ao uso dos dispositivos.

Levantamento realizado por Simonnot (2010) apurou que a relação entre os DAl e o conceito de "mídia" remete pioneiramente à pesquisa de Brigitte Jaunals (2003). Simonnot (2010, p.99, tradução nossa) assevera que a ideia de dispositivo de acesso à informação dessa pesquisadora francesa

reflete melhor, por um lado, a diversidade das aplicações desenvolvidas e, por outro, o caráter híbrido desses objetos de estudo, assim como suas dimensões não somente técnicas, mas também simbólicas e relacionais. [...] A noção de dispositivo destaca, segundo a autora, a organização e o agenciamento dos elementos heterogêneos postos em jogo, assim como suas relações estabelecidas, seu modo de interdependência, a maneira pela qual o dispositivo coloca em relação seus atores. [...] 0 dispositivo não designa somente uma reunião de objetos técnicos, ele engloba uma dimensão humana, implicando relações entre pessoas e objetos. [...] A noção destaca, assim, uma relação de interdependência entre o funcionamento dessas ferramentas materiais, computadores e a atividade humana ${ }^{9}$.

Segundo Simonnot (2010), essa noção permite considerar as diferentes lógicas - dos desenvolvedores e dos usuários observadas por Jaunals (2003) ao explicitar per se que toda a situação de comunicação é desenvolvida em um dispositivo peculiar, constituído por um ambiente físico definido em conjunto com as condições materiais e obrigatórias para a realização do ato de comunicar. 0 dispositivo comparece então, na perspectiva de Jaunals (2003), como atinente a um universo mais complexo, equivalente o próprio contrato de comunicação, tendo em vista a sua participação, sempre decisiva, na interpretação possível da mensagem em jogo.

Nessa direção, no contexto da pesquisa de informações on-line, Daniel Peraya (1999, p.153, tradução nossa), ao abordar 0 processo de comunicação mediada, define dispositivo como

um conjunto de meios colocados a serviço de uma estratégia, de uma ação com finalidade, planejada visando a obtenção de um resultado. Um dispositivo é uma instância, um lugar social de interação e de cooperação com suas intenções, seu funcionamento material e simbólico, enfim, seus modos de interação próprios. A economia de um dispositivo - seu funcionamento-, determinada por suas intenções, se apoia na organização estruturada de bens materiais, tecnológicos, simbólicos e relacionais, que modelam, a partir de características próprias, os comportamentos e as condutas sociais (afetivas e relacionais), cognitivas e comunicativas dos sujeitos ${ }^{10}$.

Essa espacialização infraestrutural e imaterial de relações leva Simonnot (2010) a valorar a noção de mediação como determinante para a caracterização de um dispositivo. Para ela, novos mediadores podem ainda emergir nesse arranjo de interações, condicionando relativamente à aceitação das finalidades do dispositivo e/ou fazendo-o se desenvolver com base nas demandas dos usuários. Falar de dispositivos de acesso à informação, assevera Simonnot (2010), não é só ultrapassar uma abordagem funcional das tecnologias digitais, mas também sobrelevar o estudo sobre como se separam seus meios e seus fins e, mais amplamente, sobre a evolução dos jogos de poder entre os atores do qual os dispositivos participam de forma específica. Assim, numa síntese significativa, a autora afirma que

\footnotetext{
9 No original: "Selon elle, l'expression rend mieux compte, d'une part, de la diversité des applications développées et, d'autre part, du caractère hybride de ces objets d'étude ainsi que de leurs dimensions non seulement techniques, mais aussi symboliques et relationnelles. [...] La notion de dispositif met l'accent, selon cet auteur, sur l'organisation et l'agencement des éléments hétérogènes qui entrent en jeu, ainsi que sur les relations qu'ils entretiennent, leur mode d'interdépendance, la façon dont le dispositif met en relation leurs acteurs. [...] Le dispositif ne désigne pas seulement un assemblage d'objets techniques, il englobe une dimension humaine impliquant des relations entre personnes et objets. [...] La notion souligne ainsi une relation d'interdépendance entre le fonctionnement de ces outils matériels, logiciels et l'activité humaine".

10 No original: "un dispositif se constitue d'un ensemble de moyens mis au service d'une stratégie, d'une action finalisée, planifiée visant à l'obtention d'un résultat. Un dispositif est une instance, un lieu social d'interaction et de coopération possédant ses intentions, son fonctionnement matériel et symbolique enfin, ses modes d'interaction propres. L'économie d'un dispositif - son fonctionnement - déterminée par les intentions, s'appuie sur l'organisation structurée des moyens matériels, technologiques, symboliques et relationnels qui modélisent, à partir de leurs caractéristiques propres, les comportements et les conduites sociales (affectives et relationnelles), cognitives, communicatives des sujets".
} 
a noção de dispositivo permitiria dar conta da heterogeneidade dos elementos - técnicos, artefatos ou atores humanos participantes, mas também, principalmente, da dinâmica das relações ocasionadas por esse conjunto que esconde as disputas de poder; e possibilita estender a análise além dos aspectos puramente técnicos. (Simonnot, 2010, p.100, tradução nossa)11

Essa macroarticulação típica do dispositivo pode ser constatada na argumentação de diversos autores que participaram da obra coletiva Les dispositifs d'information et de communication(2010), anteriormente mencionada. Dentre eles, destacam-se Bernard Jacquemin, ao tratar da Wikipédia; Bénédicte Toullec, ao abordar blogshospedados em websites de jornais; e Hélène Boulanger e Guillaume Rauscher, que analisam blogs jornalísticos (J-Bogs).

\section{A PROMESSA COMO DISPOSITIVO}

A contextualização teórica anterior condiciona o reconhecimento de outro movimento conceitual e semântico na matéria. Essa nova franja epistêmica diz respeito à distinção necessária entre os DAI, de Simonnot, ou os dispositivos de comunicação mediada, de Petraya, e os dispositivos não tecnológicos de comunicação que explicitam esta última como princípio organizador de relações de poder, seja no espaço corporativo, seja em outros campos sociais. Grosso modo, otimizando a compreensão das diferentes categorias de dispositivo de comunicação, Gonçalves (2019) os divide entre mediáticos - como as redes sociais, os websites e as publicações - e não mediáticos (mas ainda assim comunicacionais), como as promessas (D'almeida, 2012).

Este último aspecto merece especial atenção. A questão da promessa constitui temática pouco estudada no Brasil no campo de estudos sobre a comunicação organizacional e afins. Nicole D'Almeida (2012, p.257) afirma que a promessa funciona como um dispositivo. Para a autora, a promessa é uma

resposta ao problema da confiança e a uma de suas formas possíveis. Ela é a resposta, ao mesmo tempo, mais fundamental e mais frágil, tendo em vista que não engaja outras mediações além das verbais. [...] A promessa é um horizonte de relação, um mundo hipotético comum, mas necessário e que torna possível o comércio entre os homens. Não adotar essa hipótese necessária implica colocar-se fora do jogo, tornar-se estrangeiro aos homens. [...] A promessa inquieta assim como acalenta, convida tanto à desconfiança quanto à confiança. [...] A promessa é um processo dinâmico de construção de uma relação de troca fundada na antecipação. É uma maneira de organizar a relação pela configuração dos tempos de troca. (D'Almeida, 2012, p.249-252, tradução nossa) ${ }^{12}$

A promessa é um esquema de base fundamental na área das relações públicas, do marketing, da propaganda e da publicidade e, em especial, para a construção de uma marca. D'Almeida (2012, p.53-254, tradução nossa) assim disseca seus elementos semióticos:

A função de descrição de um produto empenhada por uma marca passa pela criação de um nome próprio dotado de associações, de imagens, de significações que distinguem, caracterizam e conferem um valor simbólico específico. Os objetos ganham vida e sentido quando damos a eles um nome, uma identificação [...]. Toda marca é uma promessa de valor adicionado ao imaginário e que se sobrepõe ao do produto. [...] Trata-se de construir e encarnar uma promessa em sistema de signos gráficos, sonoros, cromáticos,

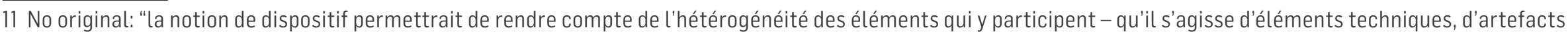

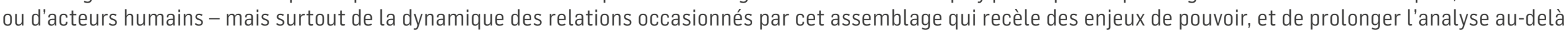
des aspects purement techniques".

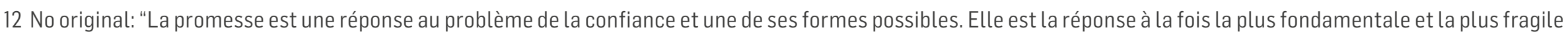

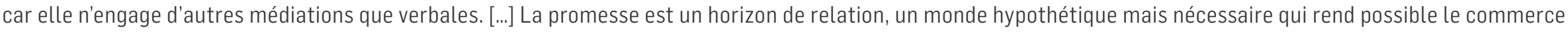

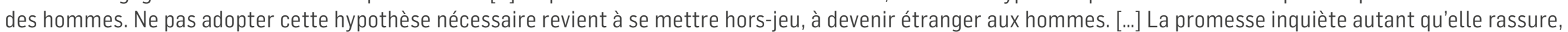

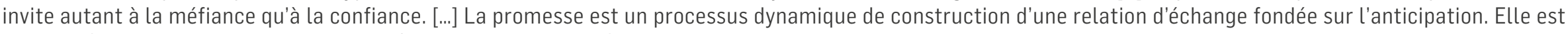
une manière d'organiser la relation en configurant le temps de l'échange".
} 
como se a palavra devesse parecer a coisa. [...] Toda marca é uma promessa, ou seja, um engajamento garantido no tempo e no espaço. [...] 0 discurso da marca e da publicidade é um sistema de multiplicação e de aceleração de promessas ${ }^{13}$.

Em qualquer aspecto público da comunicação corporativa (institucional e/ou mercadológica), a promessa é, como engenho simbólico, sua matéria-prima. Vice-versa, as estratégias de comunicação concedem estrutura e visibilidade à promessa, ela mesma sendo ingrediente matricial e finalidade precípua dessas estratégias. A lógica da promessa articula, em complexas injunções imanentes, produto, marca e instituição, de tal maneira que não deixa de recobrar pendores históricos e morais. D'Almeida (2012, p.254, tradução nossa) assim apreende essa tessitura:

A comunicação das organizações econômicas adiciona às promessas do objeto e da marca a promessa da instituição, promessa contida no que chamamos de imagem. A imagem das empresas pode ser concebida como uma reativação da lógica da honra que consiste em ter sua conversa e respeitar os engajamentos livremente estabelecidos. A comunicação institucional amplifica a comunicação de marca, ancorando-a na promessa dos objetos sob a promessa da instituição. [...] A comunicação institucional engaja a concepção de dever a que as organizações econômicas se dão $0^{14}$.

Por pressuposto, o engenho simbólico da promessa abrange, desde a origem de sua concepção até o destino final da comunicação interna ou externa, mercadológica ou institucional, a totalidade dos destinatários, sejam eles consumidores, acionistas, funcionários ou governo. Esse arco operacional não patenteia senão que a sociedade inteira se subsume a priori na lógica da promessa, esquema que, como projeto específico e pronto, se põe em diálogo aberto com a própria época em que se gesta, circula, catalisa, se esgota e desaparece, cedendo lugar a outros engenhos teleológicos.

Não por outro motivo, Gonçalves (2019) assevera que não se pode olhar consistentemente para as estratégias de promessa presentes na comunicação nas organizações sem levar em consideração sua dimensão política (lato sensu). 0 resultado de sua pesquisa ressaltou o fato de que o dispositivo, longe de ser exclusivamente cativo do universo tecnológico - de equivaler, por exemplo, ao que se designa por "mídias", devices, "ferramentas" ou canais de comunicação - e por configurar-se, antes, no plano simbólico do social, abrange, de fato e centralmente, no que tange à vida das organizações, a dinâmica estrutural da promessa da comunicação (D'almeida, 2012; Gonçalves, 2019). Conforme Gonçalves (2019), a promessa constitui, nesse sentido, o grande e poderoso dispositivo que movimenta e engaja os diversos sujeitos sociais, especialmente os públicos das organizações corporativas. Igualmente, a promessa é o vórtice simbólico que, amalgamando recursos técnicos e tecnológicos disponíveis, carreia maior visibilidade e adesão à marca de uma empresa, ampliação de fatias de mercado e melhores resultados econômico-financeiros. Diz Gonçalves (2019, p.117, grifos da autora), em palavras reconfirmáveis para este estudo:

Tendo em vista a origem foulcaultiana do termo dispositivo e as acepções sobre ele expostas, bem como a discussão em torno do dispositivo promessa, sustentamos aqui que as empresas obtêm seus resultados com o auxílio, o suporte e a estruturação de manipulações comunicacionais realizadas por meio de dispositivos-mediáticos ou não, como as promessas-dotados de técnica, aura política e finalidade financeira.

\footnotetext{
13 No original: "La fonction de signalement du produit que remplit tout marque passe par la création d'un nom propre doré d'associations, d'images, de significations distinctives qui lui confèrent une valeur symbolique spécifique. Les objets prennent vie et sens quand on leur a prêté un nom, leu identification est possible lorsque leu n nom est établi ainsi que son cortège de prédicats et d'attributs. Toute marque est une promesse de valeur ajoutée imaginaire qui se superpose à celle du produit. [...] Il s'agit de construire et d'incarner une promesse dans un système de signes graphiques, sonores, chromatiques, comme si le mot devait ressembler à la chose. [...] Toute marque est une promesse, c'est-à-dire un engagement assuré dans le temps et l'espace. [...] Le discours de la marque et de la publicité est un système de multiplication et d'accélération des promesses".

14 No original: "La communication des organisations économiques ajoute aux promesses de l'objet et de la marque la promesse de l'institution, promesse contenue dans ce que l'on appelle son image. L'image des entreprises peut être conçue comme réactivation de la logique de l'honneur qui consiste à tenir sa parole et à respecter des engagements librement prescrits. La communication institutionnelle amplifie la communication de marque en ancrant la promesse des objets sur la promesse de l'institution. [...] La communication institutionnelle engage la conception du devoir que se donnent les organisations économiques".
} 


\section{PROMESSA DA COMUNICAÇÃO, MACRODISPOSITIVO DO SOCIAL E REPRODUÇÃO DO CAPITALISMO}

A mesma apreensão do vulto político da promessa da comunicação corporativa que testemunha o pertencimento dele à dinâmica maior do social não desvela senão a abrangência do processo inteiro.

De diferentes angulações sobre a matéria - a promessa como dispositivo corporativo e, vice-versa, a comunicação corporativa que se utiliza dessa promessa, entre outras variantes organizacionais -, as tendências, no campo dos discursos e das relações de poder que eles implicam, enquadram-se, efetivamente, no dispositivo de modo geral, quer dizer, no macrodispositivo do social como conjunto de saberes e poderes, discursos e práticas articulados na forma de uma época histórica. E não surpreende que essa mesma temporalidade seja a que, em regra, faz os sujeitos sentirem, pensarem, se expressarem e agirem - enfim, serem - de tal ou qual modo (e não majoritariamente de outros possíveis), em conformidade com o próprio dispositivo maior, no todo implicado na reprodução social-histórica do status quo.

Neste ponto, o compasso reflexivo não consegue evitar ressalvas pró-forma. 0 fato de o dispositivo da comunicação e, com ele, a promessa da comunicação no espaço corporativo serem, na verdade, "dispositivos sociais" dispensaria explicitação, não fossem os rigores requeridos da própria obviedade explicativa: forma de ação economicamente orientada, inexiste invenção ou empreendimento corporativo que, desde sua concepção até suas consequências, não seja essencialmente social. A própria qualificação do dispositivo como "social" ressoa como non-sense, haja vista o pleonasmo pressuposto. Por ângulo reverso (e talvez menos óbvio), o dispositivo corporativo-comunicacional constitui a forma atual pela qual o dispositivo geral se insere no universo das organizações. Reconhecendo-o ao modo extenso: o dispositivo de comunicação e seu desdobramento na forma corporativa da promessa da comunicação constituem formas setoriais do macrodispositivo. No cerne dessa escultura, a promessa é o corolário histórico-conjuntural do arranjamento discursivo desse dispositivo institucionalizado e vinculado ao mercado, o modo idiossincrático de sua ocorrência comunicativa na esfera empresarial, por mais internamente diverso ou específico que ele se apresente (no âmbito deste ou daquele empreendimento privado).

As notações apresentadas, malgrado o pomo de evidência e tautologia em sua parte inicial, recobram, com efeito, cariz crucial em razão da necessária admissão de suas consequências teóricas (e, portanto, políticas). A promessa como dispositivo no espaço corporativo vigora, por seu enraizamento social, como motor comunicacional de desenvolvimento do capital e de reprodução social-histórica de seu modelo de sociedade e de vida cotidiana. Essa equação, por injunções imanentes e extensas, não reconfirma senão a escala da posição social da referida promessa no contexto histórico hodierno.

A essa altura da explanação, os detalhes empíricos desse dimensionamento sumariam-se a olhos vistos. Para além de a promessa da comunicação implicar no processo de construção da marca de uma empresa por estratégias de marketing, de publicidade, propaganda e/ou de relações públicas, sua lógica abrange, num mesmo ciclo operacional, o produto comercializado e sua circulação, a organização empresarial e sua luta por credibilidade, o público-alvo e seus modos de consumo, e assim por diante. Ainda - deve-se lembrar -, a força axiomática dessa lógica radica na própria formulação de discursos (no e a partir do espaço corporativo), na mobilização de tecnologias (sociais per se) e na catalisação de sujeitos (dos produtores aos consumidores). A promessa da comunicação se projeta, assim, sobre um raio significativo de funcionamento da própria sociedade.

0 reescalonamento entrevisto comporta refinos. Em termos político-axiológicos, se, do ponto de vista social-histórico, a relevância do dispositivo comparece inequívoca nas operações tecnossimbólicas das organizações, mais incomparável se torna sua função quando observada sob o prisma da dimensão política anteriormente mencionada. A dedução é semelhante, com aditamentos importantes: a volatilização desse prisma alcança a lógica do macrodispositivo do social 
tal como ele se implica na pretensa perpetuação atual - caótico-aleatória - do capitalismo. Conforme sinalizado antes, a dimensão sociopolítica da comunicação organizacional entrega, na totalidade, o caráter de armadilha da "promessa como dispositivo".

Nesse aspecto, para encerrar este estudo, vale dissecar sucintamente o modus operandi de inserção desse dispositivo no social, em fidelidade ao sentido originário, político, de dispositivo, conforme descortinado por Foucault. 0 arco dessa relação se clarifica quando se o ambienta na episteme peculiar de vertente biopolítica (na perspectiva lacaniana de Deleuze), especificamente no que tange à politização do desejo como força social matricial - para o bem e/ou para o mal. Entretecido em e com saberes, discursos e práticas, o macrodispositivo do social - nos termos assentados no início do texto -, se arranja como artifício impessoal de poder e dissuasão partout, no qual, pelo qual e a partir do qual se auto-oblitera no diapasão perceptivo do senso comum: o dispositivo sempre exige dos sujeitos que, ao pensarem, sentirem, falarem e agirem, sejam o que o dispositivo deseja que as subjetividades e os modos de subjetivação sejam; e que eles, sujeitos, remanesçam com a sensação de que o pensado, o sentido, o falado e o atuado se subordina à independência e ao arbítrio individual por conta e risco próprios -, quando, na realidade, realizam tão somente o que o dispositivo deseja de todos. Em particular, os discursos, como manifestação culturalmente estruturada de poderes e saberes fincados direta ou indiretamente na obediente invisibilidade de interesses inconfessos, não são senão formas social-históricas de desejo objetivado em linguagem e, caso queira, mais especificamente, objetificado na forma do mundo extenso. Por natureza, esse desejo, como o poder e o inconsciente, do início ao fim configura processo invisível, somente apreensível por suas reverberações. Por esse motivo, mais ausente ou obliterado na percepção comum do que na especializada, o desejo é, ainda assim, imperscrutável em todas as suas significações. Discursos desejam sujeitos, como as paixões catalisam paradoxalmente o fundamental para se consumarem enquanto se consomem na incessante busca por sobrevivência. Ao assumirem para si o desejo do mundo, os sujeitos colaboram, de modo conservantista, para a reprodução do que apela à subjetividade e recobra a corporalidade; e o fazem sem ter consciência cabal do processo, para além da lógica da armadilha em que se inserem.

Mutatis mutandis, no que tange essencialmente à lógica do macrodispositivo do social, verifica-se dinâmica relativamente similar na relação entre as organizações corporativas e o contexto socioeconômico em que se inserem e para cuja construção contribuem. Na razão e na medida de sua própria sobrevivência no contexto da intensa concorrência multilateral, as empresas, sobretudo as monopolistas e oligopolistas, operam o que esse macrodispositivo delas requer, ao mesmo tempo em que 0 fomentam, como espectro invisível, na empiria processual da vida socioeconômica. Nesse movimento paradoxal, elas esculpem as tendências majoritárias no e do capitalismo tecnológico que, ao fim e ao cabo, terminam por escapar ao próprio controle das instâncias empresariais, bem como dos órgãos que lhes representam os interesses (explícitos ou inconfessos) na esfera institucional do Estado. A fleuma organizacional como "sujeito da ação" resta, pois, dissolvida simultaneamente no fato de ele também ser megaobjeto (e, portanto, refém) das imponderabilidades social-históricas (com efeitos de cooptação) no e do referido macroprocesso.

Neste ponto, a reflexão alcança a transpolítica peculiar da relação entre promessa da comunicação, macrodispositivo do social e reprodução do capitalismo. Essa franja fenomênica, porém, anima um compasso argumentativo inteiramente outro, aberto a explorações vindouras.

\section{REFERÊNCIAS}

AGAMBEN, Giorgio. 0 que é um dispositivo? Outra Travessia, Florianópolis, n.5, p.9-16, 2005.

AGAMBEN, Giorgio. Che cosè un dispositivo? Roma: Nottetempo, 2006. 
AGAMBEN, Giorgio. O que é o contemporâneo? E outros ensaios. Chapecó: Argos, 2009.

APPEL, Violaine; BOULANGER, Hélène; MASSOU, Luc. Dispositifs : discerner, discuter, distribuer. In: APPEL, Violaine; BOULANGER, Hélène; MASSOU, Luc (org.). Les dispositifs d'information et de communication : concept, usages et objets. Bruxelles: De Boeck, 2010. p. 9-18.

APPEL, Violaine; HELLER, Thomas. Dispositif et recherche en communication des organisations. In: APPEL, Violaine; BOULANGER, Hélène; MASSOU, Luc (Org.). Les dispositifs d'information et de communication : concept, usages et objets. Bruxelles: De Boeck, 2010. p.39-57.

D'ALMEIDA, Nicole. Les promesses de la communication. Paris: Presses Universitaires de France, 2012.

DELEUZE, Gilles. Foucault. São Paulo: Brasiliense, 1991.

DELEUZE, Gilles. O mistério de Ariana. Lisboa: Passagens, 1996.

DELEUZE, Gilles. Que és un dispositivo? In: BALIBAR, Ettiénne etal. Michel Foucault, filósofo. Barcelona: Gedisa, 1999. p.155-163.

FOUCAULT, Michel. Microfísica do poder. 3. ed. Rio de Janeiro: Graal, 1982.

FOUCAULT, Michel. Vigiar e punir. Petrópolis: Vozes, 1987.

FOUCAULT, Michel. História da sexualidade l: a vontade de saber. 16. ed. Rio de Janeiro: Graal, 2005.

FOUCAULT, Michel. Segurança, território e população: curso no Collège de France (1977-1978). São Paulo: Martins Fontes, 2008a.

FOUCAULT, Michel. Nascimento da biopolítica: curso no Collège de France (1978-1979). São Paulo: Martins Fontes, 2008b.

GAVILLET, Isabelle. Michel Foucault et le dispositif : questions sur l'usage galvaudé d'un concept. In: APPEL, Violaine; BOULANGER, Hélène; MASSOU, Luc (Org.). Les dispositifs d'information et de communication: concept, usages et objets. Bruxelles: De Boeck, 2010. p.17-38.

GONÇALVES, Daniela Norcia. Comunicação organizacional no mercado financeiro contemporâneo: estratégias mediáticas de grandes companhias na era digital. 2019. 399f. Tese (Doutorado em Comunicação e Semiótica) - Pontifícia Universidade Católica de São Paulo, São Paulo, 2019.

JACQUINOT-DELAUNAY, Geneviève; MONNOYER, Laurence (coord.). Hermès - Le dispositif entre usage et concept. Paris: C.N.R.S., 1999. n.25.

JAUNALS, Brigitte. La culture de l'information: du livre au numérique. Paris: Hermès Sciences; Lavoisier, 2003. p.374-376.

ORNICAR? Bulletin périodique du champ freudien. Paris: Lyse, 1977. n.10, p.62-93.

PERAYA, Daniel. Médiation et médiatisation : le campus virtuel. Hermès, Paris, n.25, p.153-167, 1999. 
SARTRE, Jean-Paul. O que é a subjetividade?Rio de Janeiro: Nova Fronteira, 2015.

SIMONNOT, Brigitte. Les moteurs commerciaux comme dispositifs d'accès à l'information en ligne. In: APPEL, Violaine; BOULANGER, Hélène; MASSOU, Luc (Org.). Les dispositifs d'information et de communication: concept, usages et objets. Bruxelles: De Boeck, 2010. p.95-115.

ŽIŽEK, Slavo. Bem-vindo ao deserto do real. São Paulo: Boitempo, 2003. (Coleção Estado de sítio).

Artigo recebido em 12.08.2020 e aprovado em 13.10.2020. 